\title{
Evaluation of CT angiography findings in the patients with clinical diagnosis of pulmonary thromboembolism
}

\author{
Sharifi K $\mathbf{K}^{1}$, Rezaei $\mathbf{M}^{2}$, Roshani $\mathbf{D}^{3}$, Bostani $\mathbf{M}^{4}$ \\ 1. Assistant Professor, Department of Radiology, Faculty of Medicine, Kurdistan University of Medical Sciences, Sanandaj, \\ Iran (Corresponding Author), Tel: +98-8733288707, Email: drsharifi53664@yahoo.com \\ 2. Associate Professor, Infertility Treatment Center, Besat Hospital, Kurdistan University of Medical Sciences, Sanandaj, \\ Iran. \\ 3. Associate Professor, Social Determinants of Health Research Center, Research Institute for Health Development, \\ Kurdistan University of Medical Sciences, Sanandaj, Iran. \\ 4. General Practitioner, Student Research Committee, Kurdistan University of Medical Sciences, Sanandaj, Iran.
}

\begin{abstract}
Background and Aim: Pulmonary thromboembolism is an important clinical problem in the patients after major surgeries and is often difficult to diagnose because of nonspecific clinical symptoms. Diagnosis of pulmonary embolism is based on medical imaging methods. The aim of this study was to evaluate the results of CT pulmonary angiographies of the patients with primary clinical diagnosis of pulmonary thromboembolism in Besat Hospital between 2014 and 2015.

Materials and Methods: This cross-sectional study included 160 patients with primary diagnosis of pulmonary embolism who had been referring to Besat Hospital from 2014 to 2015. Data were extracted from the patient's 'medical records and we used in a checklist for every patient for data collection. Using SPSS software, data were analyzed by descriptive statistics such as mean, median, standard deviation and ratio. Chi-square and t-test were used to find out the relationship between the variables.

Result: The results of this study showed that $56.3 \%$ of the subjects were female. The mean age of the participants was $45.49 \pm 18.5$ years, $25.65 \%$ were between 31 and 40 years of age and $29.4 \%$ had abnormal CT scan results indicative of a definite cause for pulmonary embolism. There was a statistically significant relationship between abnormal CT scan and the results of di-dimer test $(\mathrm{p}=0.001)$. There was also a statistically significant relationship between gender and abnormal CT scan results, so that most patients with abnormal CT scan were male $(\mathrm{p}=0.002)$. Mean age, blood pressure, di-dimer test, respiratory rate, and heart rate were higher in subjects with abnormal CT scan.

Conclusion: According to the findings of this study, male patients between 31 and 40 years of age with abnormal CT scans should be examined more closely in order to reduce the mortality rate of the patients.
\end{abstract}

Keywords: CT angiography, Pulmonary thromboembolism, Clinical diagnosis

Received: Oct 2, $2018 \quad$ Accepted: Feb 16, 2019

How to cite the article: Sharifi K, Rezaei M, Roshani D, Bostani M. Evaluation of CT angiography findings in the patients with clinical diagnosis of pulmonary thromboembolism. SJKU 2019;24(2):90-98. 


\title{
بررسى يافتههاى سى تى آزثيوكر افى در بيماران با تشخيص بالينى ترومبو آمبولى ريه
}

\author{
كريم شريفى'، معصومه رضايى'، دائم روشنى بّ، ماريا بستانى

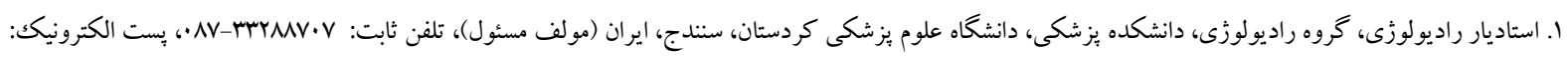 \\ drsharifi53664@yahoo.com

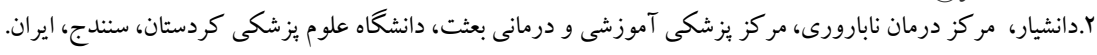

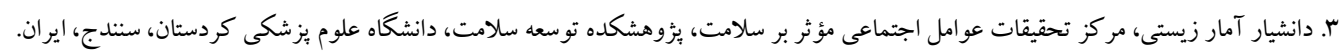

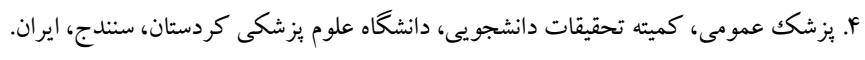

جكيده زمينه و هدف: آمبولى ريه يكك مسئله بالينى ههم در بيماران بعد از جراحىهاى بزرگك است و به علت علائم بالينى

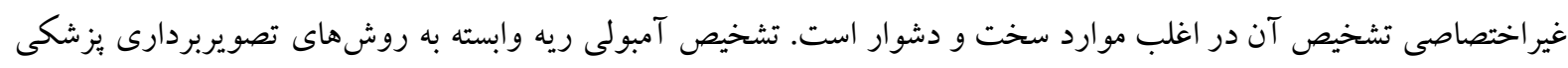

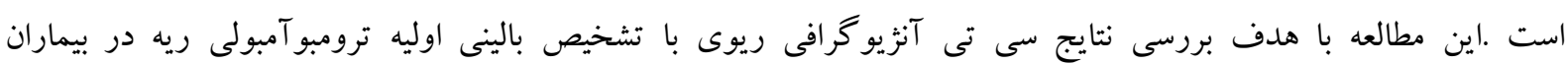

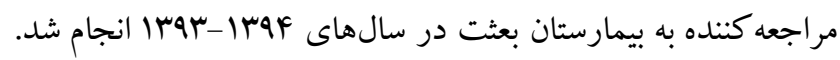

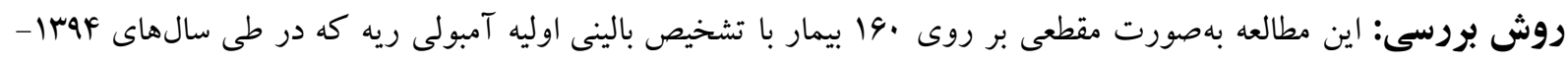

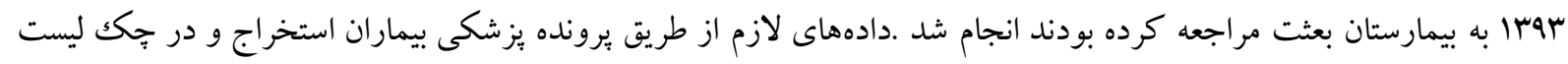

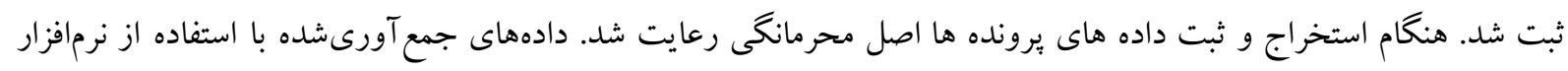

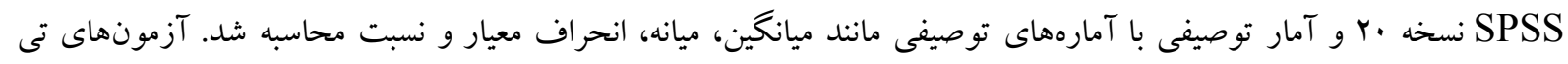

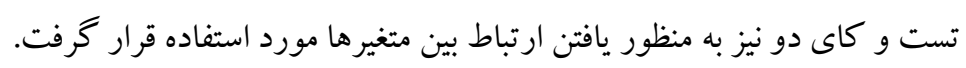

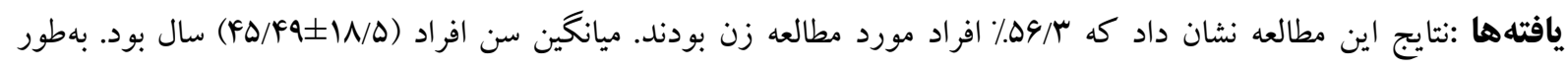

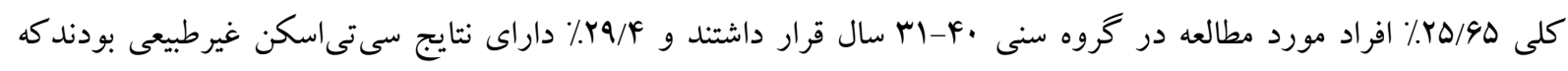

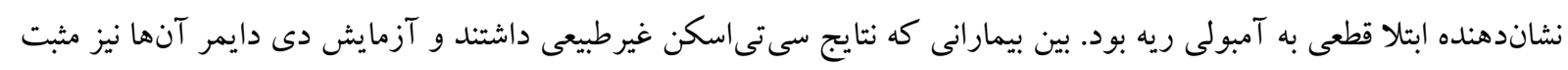

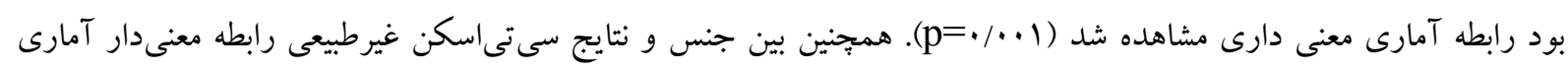

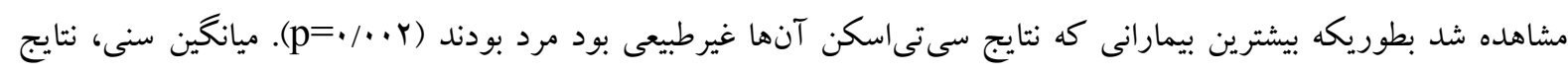

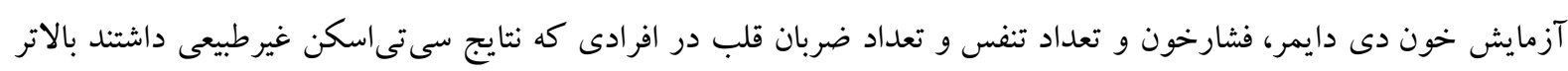

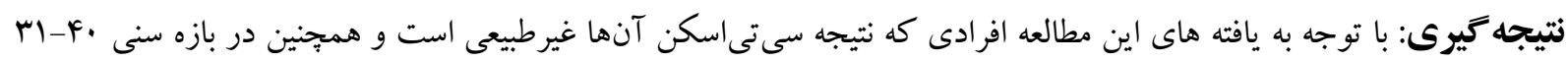

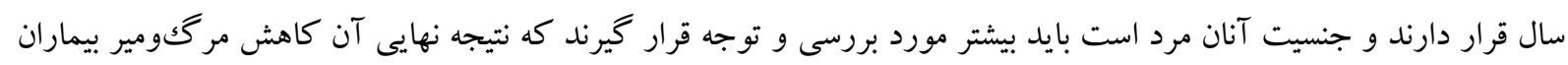

$$
\text { وصليد وازه ها: سى تى آنزيو گرافى، ترومبو آمبولى ريه، تشخيص بالينى }
$$

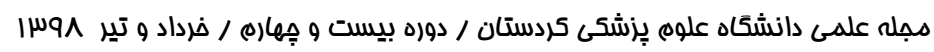




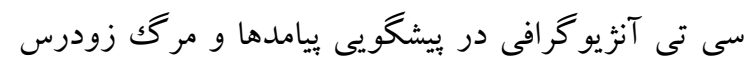

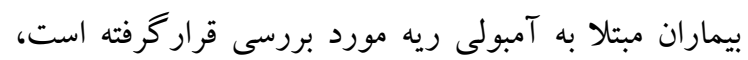

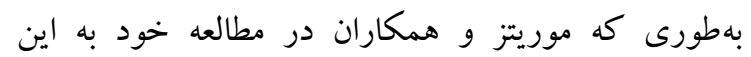

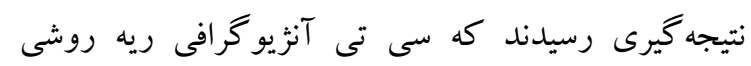

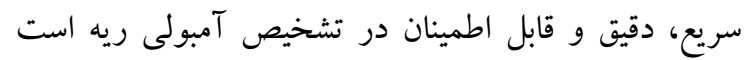

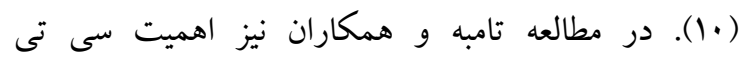

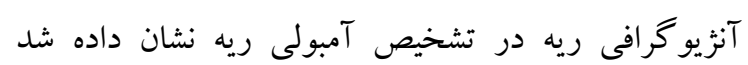

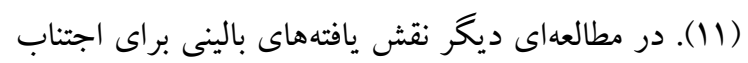

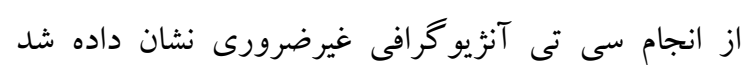

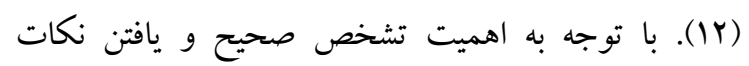

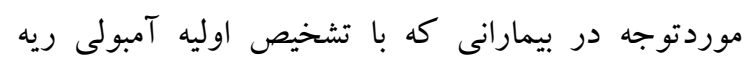

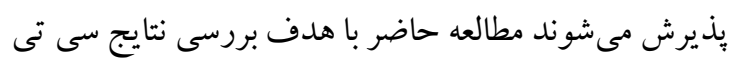

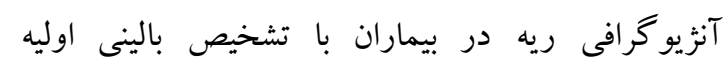

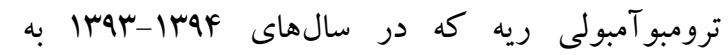
بيمارستان بعثت مراجعه كرده بودند انجام شد.

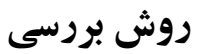

اين مطالعه مقطعى بر روى .19 بيمار با تشخيص اوليه

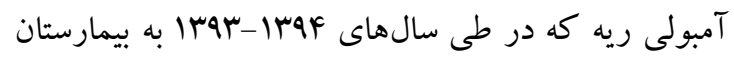

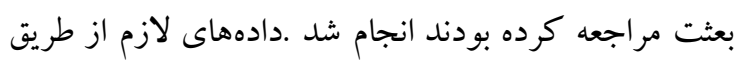

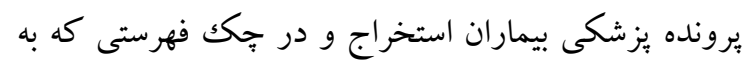
همين منظور تهيهشده بود ثبت شد. متغيرهاى سن، جنس، برد

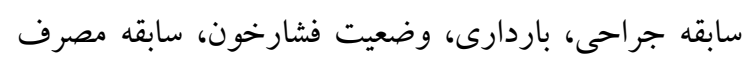

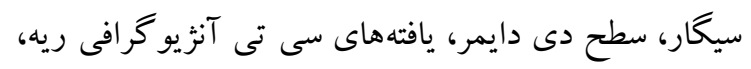

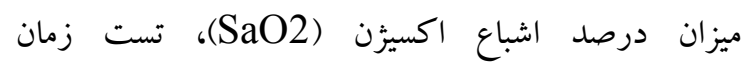
يروترمبوبين (PT) و نسبت PT بيمار به PT ميانكين طبيعى تمامى بيماران بررسى و در جّك ليست ثبت شد.

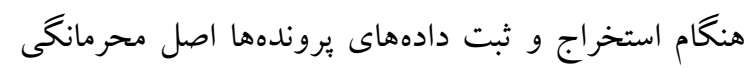
رعايت شد.

آمبولى ريه يك بيمارى شايع ثانويه به ترومبوز وريد عمقى

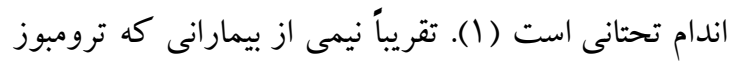

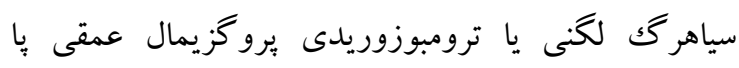

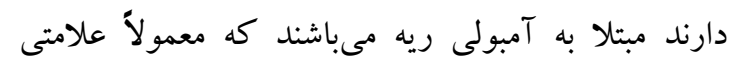

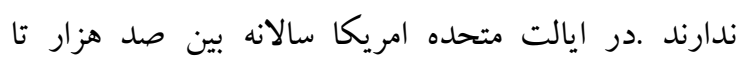

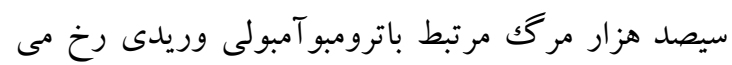
دهد و در ارويا سالانه حدود .... باآمبولى ريه رخ مىدهد (Y). ترومبو آمبولى ريوى، سومين

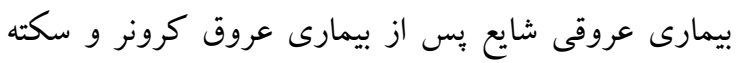

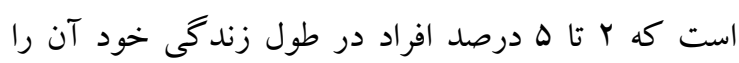

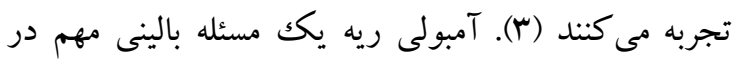
بيماران بعد از جراحىهاى بزرگك است و به علت علت علائم

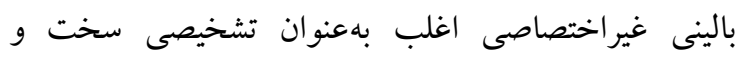
دشوار باقى مىماند (F، 1). ريسك فاكتورهاى اين بيمارى

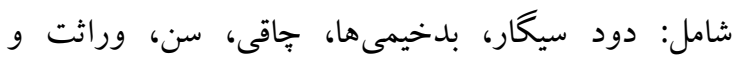
بى تحر كى طولانى و همجنين سابقه جراحى است (ه).

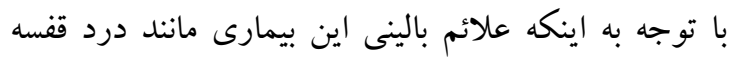

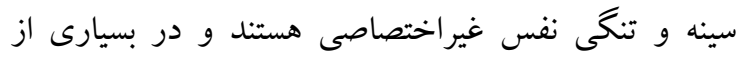

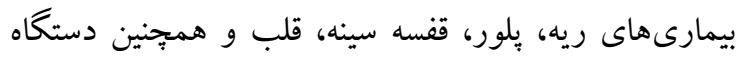

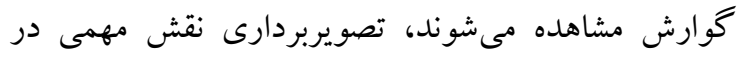
تشخيص آن دارد (9). استفاده از آنزيو گرافى، استاندارد

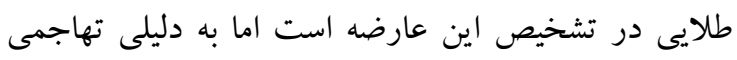
بودن و ايجاد عوارض، هزينه بالاو وسترسى محدود استفاده

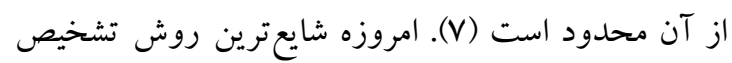

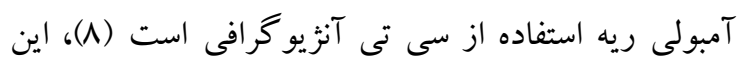

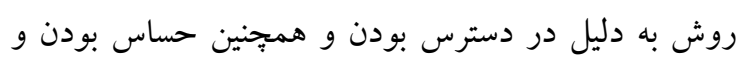

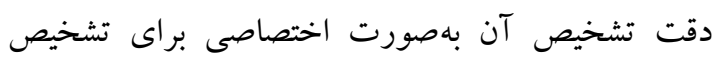

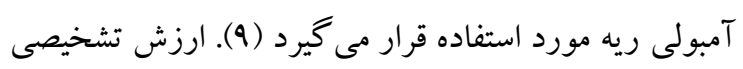




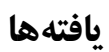

نتايج اين مطالعه نشان داد كه س/ هوها افر اد مورد مطالعه زن

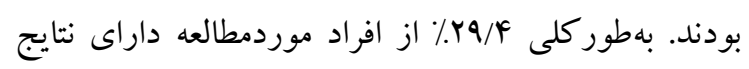
سى تىاسكن غيرطبيعى بودند. نتيجه آزمايش دى دايمر در برد

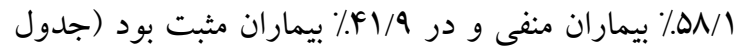

ميانگين سن افراد مورد مطالعه (1)/ه (

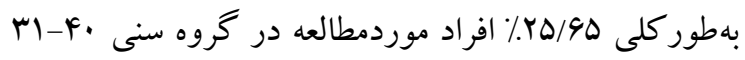

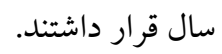

بهمنظور افزايش دقت مطالعه تمامى بيماران با تشخيص اوليه

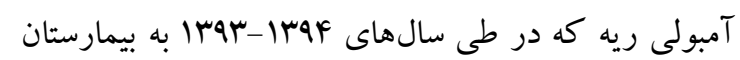
بعثت مراجعه كرده بودند به روش سرشمارى وارد مطالعه

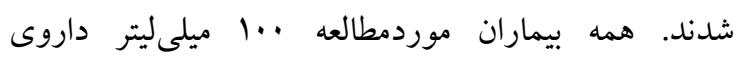
Visipaque به منظور افزايش حساسيت راديولوزى و از طريق وريدى دريافت كرده بودند.

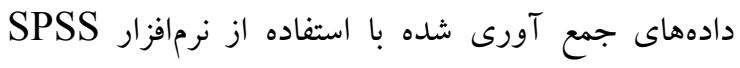
نسخه ·r و آمار توصيفى با آمارههاى توصيفى مانند ميانگين، ميانه، انحراف معيار و نسبت محاسبه شد. همجنين

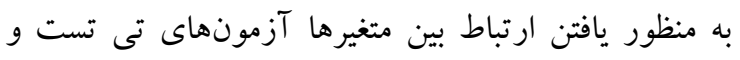

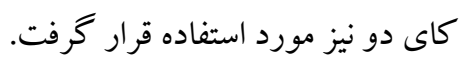

\begin{tabular}{|c|c|c|c|}
\hline درصد & تعداد & & \multirow{4}{*}{ يافته هاى سىتى اسكن } \\
\hline$v \cdot / 9$ & $11 \%$ & طبيعى & \\
\hline$r q / F$ & FV & غيرطبيعى & \\
\hline $1 \ldots$ & 19. & جمع & \\
\hline $41 / 9$ & $9 V$ & مثبت & \multirow{3}{*}{ يافتههاى دى دايمر } \\
\hline$\Delta N / 1$ & qT & منفى & \\
\hline $1 \ldots$ & 19. & جمع & \\
\hline$\Delta 9 / \mu$ & 9. & زن & \multirow{3}{*}{ جنسيت } \\
\hline $\mathrm{kr} / \Lambda$ & $v$. & مرد & \\
\hline $1 \ldots$ & 19. & جمع & \\
\hline
\end{tabular}

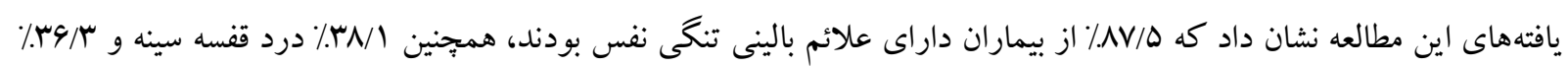

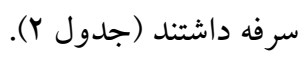

\begin{tabular}{|c|c|c|}
\hline مرصد & تعداد & علائم بالينى بـ \\
\hline$\Delta V / \Delta$ & 14. & تنكى نفس \\
\hline$r q / r$ & $\Delta \wedge$ & سرفه \\
\hline$r_{N / 1}$ & 91 & درد قفسه سينه \\
\hline $9 / \pi$ & 1. & سركيجه \\
\hline$r \mu / 1$ & $r v$ & درد شكم \\
\hline$\Delta$ & $\wedge$ & همو يتزى \\
\hline$F N / 1$ & $V V$ & بى حركتى \\
\hline
\end{tabular}

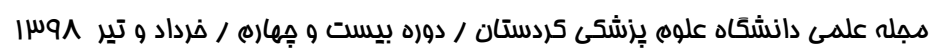




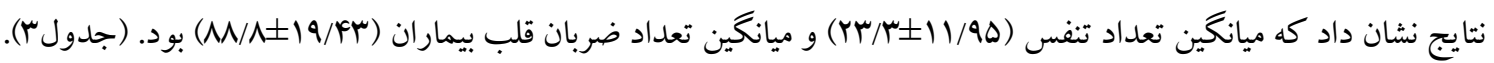
جدول rا: ميانكين و انحراف معيار متغيرهاى كمى در افراد موردمطالعه

\begin{tabular}{|c|c|c|c|c|}
\hline 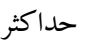 & 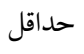 & انحر اف معيار & 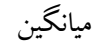 & 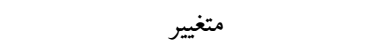 \\
\hline$\wedge \vee$ & 10 & $1 / / \Delta$ & $F \Delta / F q$ & سن \\
\hline $1 \wedge$. & $\wedge \cdot$ & $19 / \mathrm{Fr}$ & $1 Y \cdot / \Delta 9$ & فشارخون سيستوليكك \\
\hline 11. & $\wedge \cdot$ & $1 \% / \Delta \Delta$ & $V F / G Y$ & فشارخون دياستوليك \\
\hline $1 . r$ & ir & $11 / 9 \Delta$ & r & تعداد تنفس (RR) \\
\hline If. & 1. & $19 / 4 r$ & $M / \Lambda$ & تعداد ضربان قلب (PR) \\
\hline $\mathrm{V} / \mathrm{V}$ & $\cdot 1$ & $1 / 19$ & .1949 & سطح دى دايمر \\
\hline IrN & $1 \cdot / v$ & $1 \cdot / V^{4}$ & $1 F / 90$ & PT \\
\hline 4 & $\cdot 11$ &.$/ 90$ & $1 / 79$ & INR \\
\hline 1 & . & $\cdot / \cdot \wedge \mathrm{V}$ &.$/ 9 F V$ & ميزان درصد اشباع اكسيزن (SaO2) \\
\hline
\end{tabular}

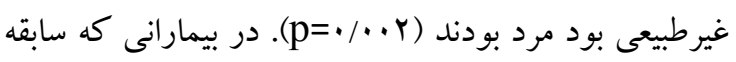

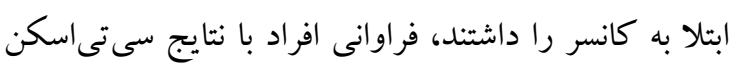

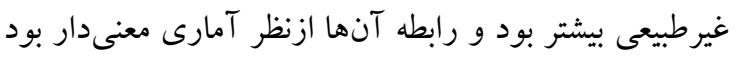

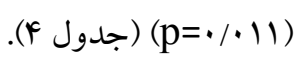

بين بيمارانى كه نتايج سىتىاسكن غيرطبيعى داشتند و

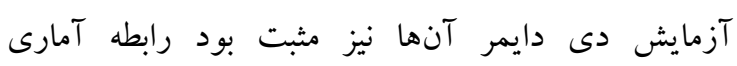

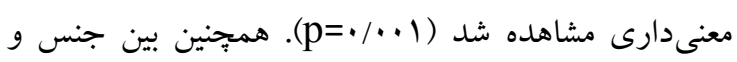
نتايج سى تىاسكن غيرطبيعى رابطه معنى دار آمارى مشاهده

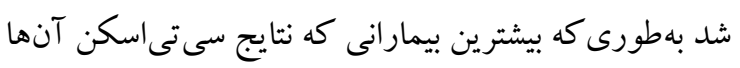

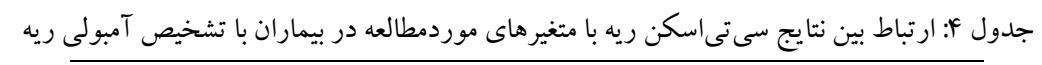

\begin{tabular}{|c|c|c|c|c|}
\hline \multirow[t]{3}{*}{ سطح معنى دار بودن } & \multicolumn{2}{|c|}{ نتايج سىتى اسكن } & \multicolumn{2}{|r|}{ متغير } \\
\hline & غير طبيعى & طبيعى & & \\
\hline & (\%) تعداد & (\%) تعداد & & \\
\hline \multirow{2}{*}{$\mathrm{p}=\cdot / \cdot \cdot 1^{*}$} & $\backslash \wedge(\boldsymbol{\mu} \wedge / \Gamma)$ & $V \Delta(99 / 4)$ & منفى & \multirow[b]{2}{*}{ تايج آزمايش دى دايمر } \\
\hline & $r q(91 / V)$ & H $(M / 9)$ & مثبت & \\
\hline \multirow[t]{2}{*}{$p=\cdot / \cdots r^{*}$} & $r V(\Delta V / F)$ & $F \Psi(r \wedge / 1)$ & مرد & \multirow[b]{2}{*}{ جنسيت } \\
\hline & $Y \cdot(F Y / G)$ & $V \cdot(91 / 9)$ & زن & \\
\hline \multirow[t]{2}{*}{$\mathrm{p}=\cdot / \kappa \mu \Delta$} & $\Delta(1 \cdot / 9)$ & $\wedge(V / l)$ & بلى & \multirow{2}{*}{ مصرف سيگار } \\
\hline & $\operatorname{Fr}(\Lambda Q / F)$ & $1 \cdot \Delta(Q Y / Y)$ & خير & \\
\hline \multirow[t]{2}{*}{$p=\cdot / r q \pi$} & $\|(\Delta \Delta)$ & If $(Y \cdot)$ & بلى & \multirow[b]{2}{*}{ سابقه باردارى } \\
\hline & $1 \cdot(F \Delta)$ & $\Delta G(\Lambda \cdot)$ & خير & \\
\hline \multirow[t]{2}{*}{$p=\cdot / \Delta q}$. & $I V(r V)$ & $F V(F \mid / 9)$ & بلى & \multirow{2}{*}{ سابقه جراحى } \\
\hline & $r q(\mathcal{G})$ & $99(\Delta \wedge / \mathcal{F})$ & خير & \\
\hline $\mathrm{p}=\cdot / \cdot 11^{*}$ & $f(\Lambda / V)$ & $1(\cdot .9)$ & بلى & \\
\hline
\end{tabular}




\begin{tabular}{|c|c|c|c|c|}
\hline & $\mathrm{Fr}(q \mid / \mathrm{r})$ & $\operatorname{lir}(99 / 1)$ & خير & سابقه كانسر \\
\hline \multirow[t]{2}{*}{$\mathrm{p}=\cdot / \kappa+\Delta$} & $F \cdot(\Lambda \Delta / 1)$ & $1 \cdots(\wedge ৭ / \Gamma)$ & بلى & \multirow{2}{*}{ تنكى نفس } \\
\hline & $V(\mid f / q)$ & $\mathbb{I r}(1 \cdot / \mathrm{V})$ & خير & \\
\hline \multirow[t]{2}{*}{$p=\cdot / \cdot \cdot q^{* * * *}$} & $r \mu(\Delta \cdot)$ & $W(9 \wedge / 9)$ & زير •ه سال & \multirow{2}{*}{ سن } \\
\hline & $r \mu(\Delta \cdot)$ & r (r/1) & الاي •ه سال & \\
\hline
\end{tabular}

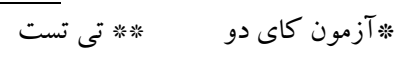

آمبولى ريه ارتباط دارد بهطورى كه با افزايش سن خطر بيمارى بيشتر خواهد شد. بين شيوع آمبولى ريه و افزايش سن رابطهاى وجود دارد و با افزايش سن، خطر بروز آمبولى بيشتر مىشود (Y) و بيشترين بروز آمبولى ريه در بيماران با سن بين ·V تا •م سال اتفاق مى افتد (r).

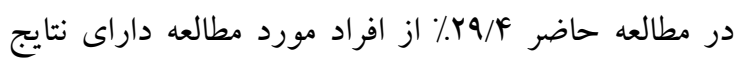

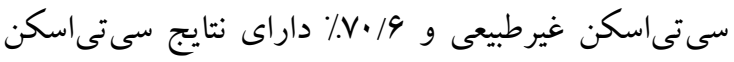
طبيعى بودند. نتيجه آزمايش دى دايمر در ه//1\% بيماران منفى و در / أl\% مثبت بود. نتايج مطالعه ما نشان داد بيشتر بيمارانى كه نتايج سىتىاسكن آنها غيرطبيعى بود، نتايج آزمايش خون دى دايمر آنها مثبت بود. آزمايش دى دايمر در حال حاضر براى رد كردن وجود سطوح بِاسماى دى دايمر بالا و درعينحال همراه با ترومبو آمبولى وريدى استفاده مى شود. اين تست آزمايشگاهى سريع، ساده و ارزان است و مىتواند از هزينهاى سنخين تستهاى تشخيصى كرانقيمت جلو گيرى كند. هنگامى كه جواب اين آزمون منفى است احتمال رد آمبولى ريه وجود دارد (If). ماوروماتيس و كسلر در مطالعه خود به اين نتيجه رسيدند كه اندازه گيرى سطح دى دايمر در رد كردن احتمال آمبولى

ريه در بيمار ان مشكو كك به اين عارضه مفيد است (ها (1).

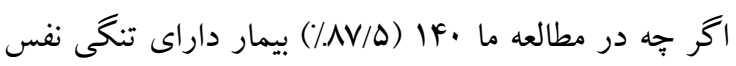
بودند و بين تنكى نفس و نتايج غيرطبيعى سىتى اسكن ريه

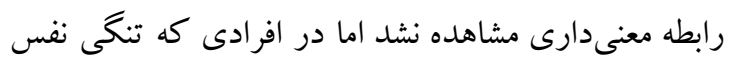

نتايج مطالعه ما نشان داد كه نتايج سىتىاسكن غيرطبيعى در افرادى كه علائم بالينى شامل سرفه، سرگيجه، درد قفسه سينه، درد شكم، همويتزى داشتند بيشتر بود. همجنين نتايج ما نشان داد كه ميانگين سن، نتايج آزمايش خون دى دايمر، فشارخون سيستوليك و دياستوليك، تعداد تنفس، تعداد ضربان قلب، درصد اشباع اكسيزن خون، PT و INR در افرادى كه نتايج سىتى|سكن غيرطبيعى داشتند بالاتر

در اين مطالعه يافتههاى سى تى آنزيو گرافى ريه در بيماران با تشخيص بالينى اوليه ترومبو آمبولى ريه در بيمارستان

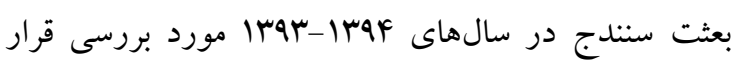
كرفت. بر اساس يافتههاى بهدست آمده س/ بوه درصد افراد موردمطالعه زن و مابقى مرد بودند. مردان بيشترين درصد نتايج سى تى اسكن غيرطبيعى را به خود اختصاص (هV/F)

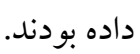
يافتها نشان داد كه ميانگين سن افراد مورد مطالعه

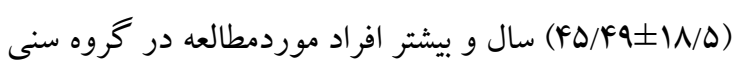

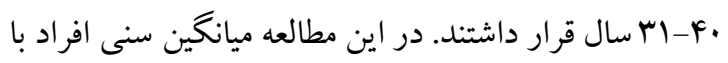
نتايج سىتى اسكن غيرطبيعى (199/ اله) سال و ميانكين سنى افراد با نتايج سىتىاسكن طبيعى (FY/A) سال بود. به نظر

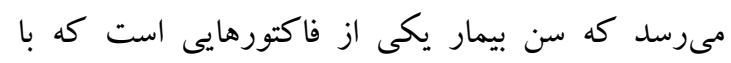


درصد از درد قفسه سينه شكايت داشتند (19). به نظر مىرسد اين سه علامت بالينى در بيشتر بيماران آمبولى ريه ديده مىشود و بايد موردتوجه قرار گيرد. علائم بالينى بيمارى آمبولى ريه غير اختصاصى هستند و تنكى نفس و درد قفسه سينه در بسيارى از عوارض قلبى و ريوى مشاهده مىشود اما بروز تنكى نفس ناگهانى بهعنوان نشانه بالينى آمبولى ريه بايد موردتوجه قرار گيرد (IV). نتايج مطالعه حاضر نشان داد كه ميانگين تعداد تنفس و تعداد ضربان قلب در افرادى كه نتايج سىتىاسكن غيرطبيعى داشتند بالاتر بود. بهطورى كه ميانگين تعداد تنفس (ML) بود. ولشان و همكاران نيز در مطالعه خود دريافتند كه بيماران مبتلابه عارضه آمبولى ريه داراى علائم بالينى افزايش تعداد تنفس و همجينين افزايش تعداد ضربان قلب بودند (·r). وست و همكاران نيز در يكك مطالعه مرورى سيستماتيك به اين نتيجه رسيدند كه بيشتر بيماران با تشخيص آمبولى ريه داراى تاكى كاردى و تاكى بينه هستند (YI) (Y) با توجه به علائم و نشانهاى آمبولى ريه شامل تاكى جينه بيشتر از بيست تنفس در دقيقه (YY) اين مطالعات با يافته هاى ما مطابقت دارند.

\section{نتيجه كيرى}

با توجه به يافته هاى اين مطالعه افرادى كه نتيجه سى تى اسكن ريه آنها غير طبيعى است و همجنين در بازه سنى .F. اس سال قرار دارند و جنسيت آنان مرد است بايد بيشتر مورد بررسى و توجه قرار گيرند. با توجه به اينكه علائم بالينى عارضه آمبولى ريه غير اختصاصى هستند توصيه مى شود بيماران با مشخصات فوق با دقت بيشترى موردبررسى قرار گيرند تا مرگك و مير اين بيماران كاهش يابد.
داشتند بيشترين درصد نتايج غير طبيعى سىتى|سكن مشاهده شد و همجينين شايعترين نشانه بالينى در بيماران تنكى نفس بود. در مطالعه شوجات و همكاران شايعترين شكايت بالينى تنگى نفس بود (19). همجِنين در مطالعه مانوئل و همكاران 91\% از بيماران مبتلا به آمبولى ريه از تنكى نفس شكايت داشتند (IV) نتايج اين مطالعات با يافته هاى مطالعه ما مطابقت دارد و به نظر مىرسد كه تنگى نفس يكى از علائم بارز آمبولى ريه باشد و بيشتر افراد داراى اين بيمارى از تنگى نفس رنج مى برند. در مطالعه حاضر ميانگين سن بيماران ( ( بود و بيشترين بيمارانى كه نتايج سىتىاسكن آنها غيرطبيعى بود مرد بودند. همجنين بين جنس و نتايج سى تىاسكن غيرطبيعى رابطه معنىدار آمارى مشاهده شد. در مطالعه تامبه و همكاران علاوه بر اينكه اهميت سى تى آنثيو گرافى ريه در تشخيص آمبولى ريه نشان داده شد، بيشترين شيوع خطر آمبولى ريه در جنسيت مرد و افراد

بالاى هاF سال بود كه با مطالعه ما همخوانى دارد (11). در مطالعه ما متغيرهايى مانند جنس، سن، مصرف سيگار، سابقه باردارى، سابقه جراحى، سابقه بدخيمى و بى حركتى بهعنوان ريسكك فاكتورها و عوامل خطر عارضه آمبولى ريه مورد مطالعه قرار گرفت. از ميان اين عوامل خطر، بين سن، سابقه بدخيمى و جنسيت و نتايج غير طبيعى سىتى اسكن ريه بيماران رابطه معنى دار آمارى مشاهده شد. استين و همكاران در مطالعه خود نشان دادند كه \&\&٪ بيماران مبتلا به عارضه آمبولى ريه حداقل يكك يا جند عوامل خطر اين عارضه را

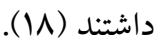

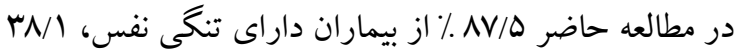
\% داراى درد قفسه سينه و ه/\$\%٪ داراى سرفه بودند. در مطالعه مانويل و همكاران نيز 41 درصد داراى تنگى نفس،

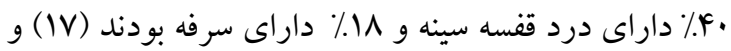
در مطالعه ناكامورا 94\% از بيماران از تنكى نفس و 49 


$$
\text { تشكر راداريم. كليه كسانى ما رادر اين يرزه يارى كرده اند كمال }
$$

\section{References}

1. Remy-Jardin M, Pistolesi M, Goodman LR, Gefter WB, Gottschalk A, Mayo JR, et al. Management of suspected acute pulmonary embolism in the era of CT angiography: a statement from the Fleischner Society. Radiol 2007;45:315-29.

2. Jameson J, Kasper D, FauciA, Hauser S, Longo D, Loscalzo J. Harrison's principles of internal medicine. 18th ed. New York: McGraw Hill Education, 2012:2170.

3. Farzamnia H, Rabiei K, Sadeghi M, Roghani F. The predictive factors of recurrent deep vein thrombosis. ARYA Atheroscler 2011;7:123-8.

4. Winkler BE, Schuetz W, Froeba G, Muth CM.N-terminal prohormone of brain natriuretic peptide: a useful tool for the detection of acute pulmonary artery embolism in post-surgical patients. Bri J Anaesth 2012;109:907-10.

5. Gjonbrataj E, Kim JN, Gjonbrataj J, Jung HI, Kim HJ, Choi W. Risk factors associated with provoked pulmonary embolism. Korean J Intern Med 2017; 32: 95-101.

6. Henzler Th, Barraza J, Nance J, Costello Ph, Krissak R, Fink Ch. CT imaging of acute pulmonary embolism. J Cardiovasc Comput Tomogr 2011;5:3-11.

7. Battal B, Karaman B, Gümüş S, Akgün V, BozlarU, Taşar M. The analysis of nonthromboembolic findings encountered in multidetector computedtomography pulmonary angiography studies in patients with suspected pulmonary embolism. Turk J Emerg Med 2011;11:1-13.

8. Burge AJ, Freeman KD, Klapper PJ, Haramati LB. Increased diagnosis of pulmonary embolism without a corresponding decline in mortality during the CT era. Clin Radiol 2008;63:381-6.

9. Woo JK, Chiu RY, Thakur Y, Mayo JR. Risk-benefit analysis of pulmonary CT angiography in patients with suspected pulmonary embolus. Am J Roentgenol 2012. 198:1332-9.

10. Albrecht MH, Bickford MW, Nance JW Jr, Zhang L, De Cecco CN, Wichmann JL, et al. State-of-the-art pulmonary CT angiography for acute pulmonary embolism. Am J Roentgenol 2017;208:495-504.

11. Tambe J, Moifo B, Fongang E, Guegang E, Juimo AG. Acute pulmonary embolism in the era of multi-detector CT: a reality in sub-Saharan Africa. BMC Med Imaging 2012;12:31.

12. Carruthers EC, Choi HK, Sayre EC, Avina -Zobieta GA. Risk of deep venous thrombosis and pulmonary embolism in individuals with polymyositis and dermatomyositis: a general population-based study. Ann Rheum Dis 2016;75:110-6.

13. Bĕlohlávek J, Dytrych V, Linhart A. Pulmonary embolism, part I: Epidemiology, risk factors and risk stratification, pathophysiology, clinical presentation, diagnosis and nonthrombotic pulmonary embolism. Exp Clin Cardiol 2013;18:129-8.

14. Crawford F, Andras A, Welch K, Sheares K, Keeling D, Chappell FM. D-dimer test for excluding the diagnosis of pulmonary embolism. Cochrane Database Syst Rev 2016; $5 ;:$ CD010864.

15. Mavromatis BH, Kessler CM. D-dimer testing: the role of the clinical laboratory in the diagnosis of pulmonary embolism. J Clin Pathol 2001;54:664-8.

16. Shujaat A, Shapiro JM, Eden E. Utilization of CT pulmonary angiography in suspected pulmonary embolism in a major urban emergency department. Pulm Med 2013;2013:915213.

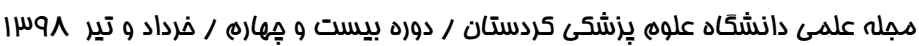


17. Manuel A, Peralta T, Salas A, Peralta T, Salas A, Silva A. Clinical profile, management and outcomes of patients with pulmonary embolism: a retrospective tertiary centre study in Angola. Cardiovasc J Afr 2017;28:356-61.

18. Stein PD, Beemath A, Matta F, Weg JG,Yusen RD, Hales CA. Clinical characteristics of patients with acute pulmonary embolism: data from PIOPED II. Am J Med 2007; 120:871879.

19. Nakamura M, Fujioka H, Yamada N, Sakuma M, Okada O, Nakanishi N. Clinical characteristics of acute pulmonary thromboembolism in Japan: results of a multicenter registry in the Japanese society of pulmonary embolism research. Clin Cardiol 2001;24:132-8. 20. Volschan A, Albuquerque DC, Tura BR, Knibel Mde F, Souza PC, Toscano ML. Pulmonary embolism: multicenter registry in tertiary hospitals. Revista Brasilia de Terapia Intensiva. 2009;21:237-46.

21. West J, Goodacre S, Sampson F. The value of clinical features in the diagnosis of acute pulmonary embolism: systematic review and meta-analysis. QJM 2007:100:763-69.

22. Courtney DM, Miller C, Smith Line H, Klekowski N, Hogg M, Kline JA. Prospective multicenter assessment of interobserver agreement for radiologist interpretation of multidetector computerized tomographic angiography for pulmonary embolism. J Thromb Haemost 2010;8: 533-9. 